\title{
AVALIAÇÃO DA ESTABILIDADE ENZIMÁTICA DO EXTRATO PECTINOLÍTICO DE Aspergillus niger ATCC 9642 IMOBILIZADO EM SUPORTE POLIMÉRICO-INORGÂNICO MINERALIZADO BIOMIMETICAMENTE
}

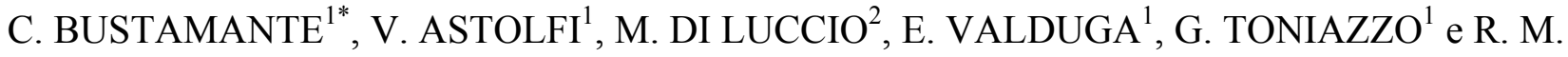 \\ DALLAGO
}

\author{
${ }^{1}$ Universidade Regional do Alto Uruguai e das Missões - URI-Erechim, Departamento de \\ Engenharia de Alimentos \\ ${ }^{2}$ Universidade Federal de Santa Catarina - UFSC, Campus Trindade, Departamento de \\ Engenharia Química e Engenharia de Alimentos - \\ E-mail para contato: cindyelena506@hotmail.com
}

\begin{abstract}
RESUMO - As técnicas de imobilização de enzimas permitem obter biocatalisadores estáveis no meio reacional, recuperáveis e reutilizáveis, possibilitando seu uso em diferentes processos industriais. Neste trabalho foi avaliada a estabilidade da atividade enzimática durante o armazenamento e reutilização do extrato enzimático pectinolítico de Aspergillus niger ATCC 9642 imobilizado no suporte biomimético híbrido polimérico-inorgânico de alginato/gelatina/oxalato de cálcio (AGOCa). A atividade pectinolítica $\left(\mathrm{U} \mathrm{g}^{-1}\right)$ foi determinada na reação de hidrólise de pectina cítrica $(0,5 \%$ $\mathrm{m} / \mathrm{v}$ ) a $73^{\circ} \mathrm{C}$ e $\mathrm{pH}$ 5,5, utilizando-se o método do ácido 3,5-dinitrosalić́lico. Considerando-se a atividade inicial como $100 \%$, obtiveram-se atividades residuais de $150,3 \%$ e $56,3 \%$ depois de 112 dias de armazenamento a $4{ }^{\circ} \mathrm{C}$ e nove reúsos, respectivamente. Estes resultados foram atribuídos ao microambiente criado pelas esferas biomiméticas que protegeram ao biocatalisador das condições externas e a camada inorgânica formada ao redor das esferas de alginato de cálcio que reduziu a lixiviação da enzima do suporte durante a reutilização do extrato pectinolítico imobilizado.
\end{abstract}

\section{INTRODUÇÃO}

As substâncias pécticas constituem um dos polissacarídeos mais complexos encontrados na natureza (Uenojo e Pastore, 2007). Sua degradação até as unidades monoméricas básicas é resultado da ação conjunta de um grupo complexo de enzimas conhecidas como pectinases, as quais, dependendo do mecanismo de ação sobre a estrutura principal da molécula de pectina, classificam-se em enzimas desesterificantes, cuja função é a liberação dos grupos acetilas (pectin acetil esterase) ou metila (pectinmetilesterases) e em enzimas despolimerizantes (poligalacturonases, polimetilgalacturonase, poligalacturonato e polimetilgalacturonato liases) (Pedrolli et al., 2009).

As pectinases têm diferentes aplicações biotecnológicas, especialmente na indústria de alimentos, onde são usadas para a produção de sucos de frutas (nas etapas clarificação e filtração), 
produção de vinhos e nos processos de extração e maceração de frutas e vegetais (Jegannathan e Nielsen, 2013; Semenova et al., 2006; Jayani et al., 2005).

Preparações comerciais de pectinases são normalmente de origem fúngicas, especialmente de Aspergillus e Penicillium, exibindo características de alta atividade de pectinametilesterase, poligalacturonase e pectina liase (Sieiro et al., 2012). Geralmente, são vendidas no estado solúvel, apresentando problemas de aplicação comuns dos biocatalisadores em solução, como a instabilidade nas condições de processo, contaminação do produto pela presença do biocatalisador e impossibilidade da sua recuperação e reutilização (Seenuvasan et al., 2013; Abdelmajeed et al., 2012).

As técnicas de imobilização são especialmente desenhadas para melhorar o comportamento das enzimas nos processos catalíticos, já que mediante estas podem ser atingidos efeitos benéficos na estabilidade, em função das interações físicas e químicas entre o suporte e as moléculas da enzima (Gomes et al., 2006). Além disso, os derivados imobilizados tornam-se facilmente recuperáveis e reutilizáveis. Os processos de imobilização devem ser métodos bem regulados, não agressivos que respeitem a estrutura nativa da proteína e, ao mesmo tempo, as ligações formadas entre a enzima e/ou suporte devem excluir os aminoácidos envolvidos diretamente na reação catalítica (Datta et al., 2013).

As enzimas podem ser imobilizadas sobre uma ampla variedade de suportes naturais ou sintéticos, a eleição do suporte e/ou a técnica depende da natureza da enzima, o substrato e a aplicação (Buga et al., 2010). Recentemente, materiais híbridos poliméricos-inorgânicos, obtidos por reações de mineralização biomimética, têm sidos considerados como a próxima geração de suportes para a imobilização de enzimas, uma vez que proveem ambientes biocompatíveis para o encapsulamento e estabilização destas, além de ser uma metodologia simples e de fácil implementação (Lu et al., 2012; Shen et al., 2011).

Neste contexto, o objetivo deste trabalho foi avaliar a estabilidade enzimática durante o armazenamento e reúso do extrato pectinolítico de Aspergillus niger ATCC 9642 imobilizado em suporte de alginato/gelatina/oxalato de cálcio (AGOCa) obtido por reações de mineralização biomimética.

\section{MATERIAL E MÉTODOS}

\subsection{Bioprodução do extrato enzimático pectinolítico}

O extrato pectinolítico foi obtido por fermentação submersa, conforme a metodologia descrita por Gomes et al. (2011). Para a bioprodução do extrato pectinolítico foi utilizado um meio sintético constituído por $32 \mathrm{~g} \mathrm{~L}^{-1}$ de pectina cítrica, $2 \mathrm{~g} \mathrm{~L}^{-1}$ de L- asparagina, $0,06 \mathrm{~g} \mathrm{~L}^{-1}$ de fosfato de potássio, $1,0 \mathrm{~g} \mathrm{~L}^{-1}$ de sulfato de ferro II. A concentração de esporos e as condições empregadas foram de $5 \times 10^{6}$ esporos $\mathrm{m} \mathrm{L}^{-1}, 180 \mathrm{rpm}, 30^{\circ} \mathrm{C}$, pH inicial de 5,5 e 24 horas, respectivamente. 


\subsection{Atividade pectinolítica do derivado imobilizado}

A atividade pectinolítica do extrato enzimático imobilizado foi determinada na reação de hidrólise do substrato pectina cítrica $(0,5 \% \mathrm{~m} / \mathrm{v})$ a $73{ }^{\circ} \mathrm{C}$ e $\mathrm{pH} 5,5$, pelo método descrito por Miller (1959) com algumas modificações. Uma unidade pectinolítica foi definida como a quantidade de enzima necessária para liberal $1 \mu \mathrm{mol}$ de ácido galacturônico por minuto

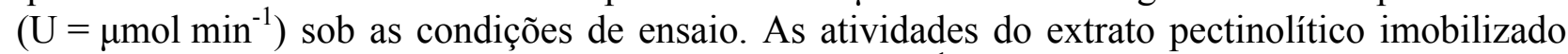
foram expressas em unidades de atividade por grama $\left(\mathrm{U} \mathrm{g}^{-1}\right)$.

\subsection{Imobilização do extrato enzimático pectinolítico}

O processo de imobilização do extrato foi adaptado da metodologia descrita por Shen et al. (2011). Alginato de sódio $2 \%(\mathrm{~m} / \mathrm{v})$ foi dissolvido em tampão oxalato de sódio $(100 \mathrm{mM}$, $\mathrm{pH} 5,5)$. Após a solubilização foi adicionado o extrato enzimático na proporção $3: 10(\mathrm{v} / \mathrm{v})$ considerando a relação extrato enzimático:tampão oxalato de sódio. $\mathrm{O}$ gel obtido foi gotejado em uma solução de $1 \%(\mathrm{~m} / \mathrm{v})$ de gelatina e $\mathrm{CaCl}_{2}(75 \mathrm{mM})$, mantida sob agitação constante. Durante 10 minutos as esferas formadas permaneceram submersas na solução de $\mathrm{CaCl}_{2}$ e gelatina. Posteriormente, foram lavadas com $100 \mathrm{~mL}$ de água destilada e $100 \mathrm{~mL}$ de tampão acetato de sódio $(100 \mathrm{mM}, \mathrm{pH} 5,5)$. Após o término do processo de lavagem, as esferas foram filtradas com a vácuo por 20 minutos e armazenadas a $4^{\circ} \mathrm{C}$.

\subsection{Estabilidade do extrato enzimático pectinolítico imobilizado}

O extrato pectinolítico imobilizado no suporte de AGOCa com atividade inicial $\left(\mathrm{U}_{\mathrm{I}}\right)$ foi armazenado a $4^{\circ} \mathrm{C}$ por 112 dias. Periodicamente, determinou-se a atividade enzimática $\left(\mathrm{U}_{\mathrm{A}}\right)$. A estabilidade do armazenamento (EA) do extrato imobilizado foi definida pela porcentagem da relação entre $U_{\mathrm{A}}$ e $U_{\mathrm{I}}$.

$$
E A(\%)=\frac{U_{A}}{U_{I}} \times 100
$$

\subsection{Estabilidade operacional}

A estabilidade operacional do extrato pectinolítico imobilizado em AGOCa foi determinada sucessivamente em diferentes ciclos de reações. A atividade pectinolítica do primeiro ciclo foi considerada como $100 \%$. Após cada um dos ciclos, o derivado imobilizado foi removido do meio reacional, lavado com água destilada e solução tampão de acetato de sódio (100 mM, pH 5,5). O excesso de solução aquosa foi removido por filtração a vácuo, sendo então realizada a dosagem de atividade empregando a metodologia descrita no item 2.3. A atividade relativa (RA) de cada ciclo foi determinada conforme a equação 2 .

$$
R A(\%)=\frac{\text { Atividade pectinolítica no ciclo } n}{\text { Atividade pectinolítica no ciclo } 1} \times 100
$$




\section{RESULTADOS E DISCUSSÃO}

A estabilidade da atividade enzimática do extrato pectinolítico imobilizado no suporte de AGOCa e armazenado a $4{ }^{\circ} \mathrm{C}$ foi avaliada durante 112 dias de estocagem. Neste período, a atividade pectinolítica do imobilizado foi dosada em intervalos de tempo regulares. A Figura 1 mostra o perfil de atividade relativa obtido após o tempo avaliado.

Figura 1- Estabilidade térmica a $4{ }^{\circ} \mathrm{C}$ do extrato enzimático pectinolítico imobilizado em suporte de AGOCa.

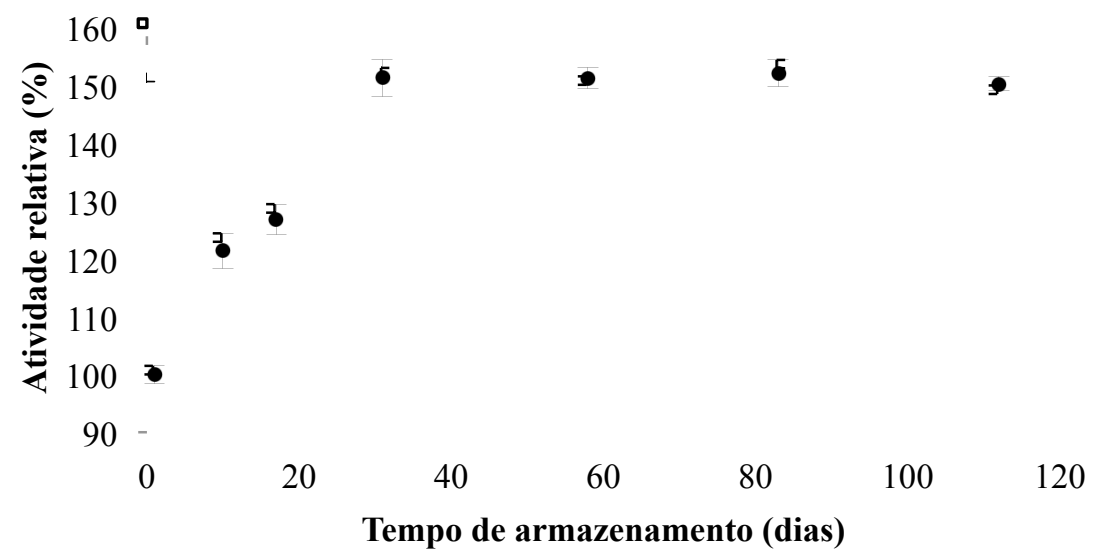

O extrato pectinolítico imobilizado manteve incremento constante da atividade relativa, obtendo-se após 112 dias de armazenamento, aproximadamente, $150 \%$ da atividade inicial. Em função dos resultados, corroborou-se que a matriz de AGOCa fornece ao extrato pectinolítico imobilizado proteção do ambiente exterior, permitindo o aumento da atividade relativa, este comportamento foi atribuído ao microambiente criado pelas esferas biomiméticas, que imitou os efeitos de aglomeração e confinamento em uma célula viva (Zhang et al., 2008).

A imobilização de enzimas tem como interesse principal a obtenção de derivados que melhorem sua estabilidade enzimática sob as condições aplicadas no processo catalítico e, ainda, que possam ser recuperados e reutilizados. Porém, ao longo dos reúsos, é comum que o biocatalisador imobilizado apresente diminuição da atividade enzimática. Esta deverá ser quantificada para determinar a estabilidade operacional do derivado imobilizado, ou seja, o número de vezes que poderá ser reutilizado, sem que se afete a produtividade do processo. A Figura 2 traz o perfil de atividade relativa obtido durante a avaliação da estabilidade operacional, em relação ao uso consecutivo do extrato enzimático pectinolítico imobilizado no suporte de AGOCa. 
Figura 2-Estabilidade operacional do extrato pectinolítico imobilizado em suporte de AGOCa

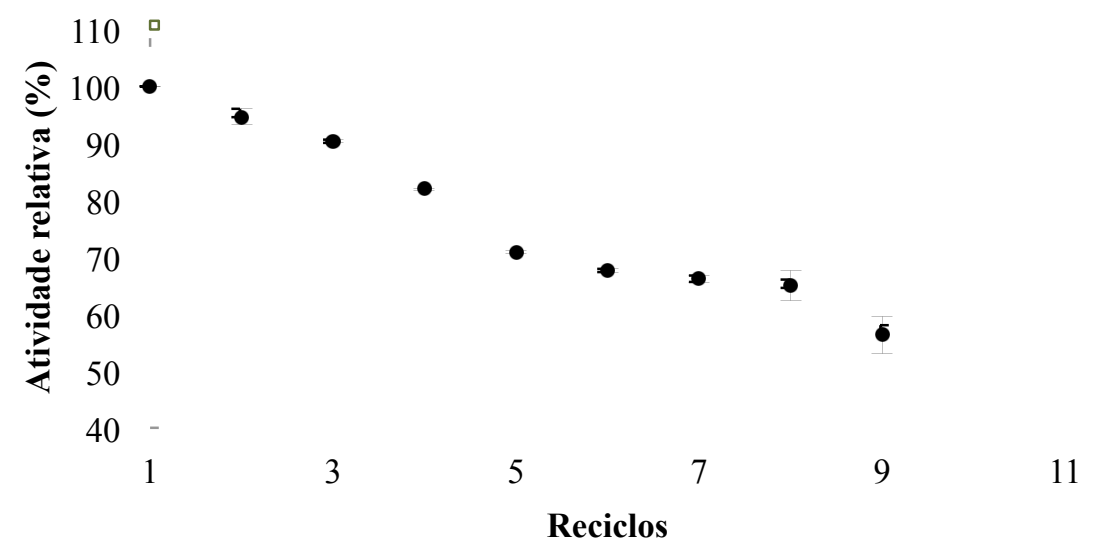

Neste estudo, demostrou-se que o extrato pectinolítico imobilizado no suporte de AGOCa pode ser reutilizado por nove ciclos consecutivos, mantendo 56,3\% de sua atividade inicial, como mostra a Figura 2.

A literatura reporta que geralmente enzimas encapsuladas em alginato de cálcio têm após uso continuo em diferentes ciclos catalíticos, diminuição da atividade enzimática pela liberação da enzima do suporte, como resultado da lavagem das esferas no fim de cada ciclo, além de mudanças conformacionais e ao dano mecânico das esferas depois de ser utilizadas repetidas vezes (REHMAN et al., 2013; WON et al., 2005). Porém, cabe salientar que os resultados obtidos neste estudo são promissores e foram atribuídos ao bom desempenho do suporte AGOCa, o qual devido à formação da camada biomimética inorgânica de gelatinaoxalato de cálcio ao redor das esferas de alginato de cálcio, minimizou a lixiviação do biocatalisador do suporte durante cada um dos ciclos catalíticos em comparação com outros estudos reportados na literatura.

\section{CONCLUSÃO}

Neste trabalho foi avaliada a estabilidade ao armazenamento e operacional do extrato pectinolítico de Aspergillus niger ATCC 9642 imobilizado no suporte biomimético poliméricoinorgânico de AGOCa. Comprovou-se que a formação da camada calcificada de oxalato de cálcio ao redor das esferas trouxe efeitos benéficos na estabilidade da atividade enzimática e no desempenho do suporte. Além disso, foi possível utilizar consecutivamente o derivado imobilizado por nove ciclos reacionais. Em geral, estas características fazem do extrato pectinolítico imobilizado em AGOCa um derivado com excelente potencial para ser utilizado na concepção de biorreatores e em diversas aplicações na indústria de alimentos. 


\section{REFERÊNCIAS}

ABDELMAJEED, N.; KHELI, O.; DANIAL, E. Immobilization technology for enhancing bioproducts industry. Afr J Biotechnol., v. 11, n. 71, p. 13528-13539, 2012.

BUGA, M.; IBRAHIM, S.; NOK, A. Physico-chemical characteristics of immobilized polygalacturonase from Aspergillus niger (SA6). Afr J Biotechnol., v. 9 n. 52, p. 89348943, 2010.

DATTA, S.; CHRISTENA, L.; RAJARAM, Y. Enzyme immobilization: an overview on techniques and support materials. 3 Biotech., v.3, p 1-9, 2013.

GOMES, J.; ZENI, J.; CENCE, K.; TONIAZZO, G.; TREICHEL, H.; VALDUGA,E. Evaluation of production and characterization of polygalacturonase by Aspergillus niger ATCC 9642. Food Bioprod Process., v. 89, n. 4, p. 281-287, 2011.

GOMES, F.; DE PAULA, A.; SILVA, G.; DE CASTRO, H. Determinação das propriedades catalíticas em meio aquoso e orgânico da lipase de Cândida rugosa imobilizada em celulignina quimicamente modificada por carbonildiimidazol. Quím Nova., v. 29, n. 4, p. 710-718, 2006.

JAYANI, R.; SAXENA, S.; GUPTA, R. Microbial pectinolytic enzymes: a review, Process Biochem, v. 40, p. 2931-2944, 2005.

LU, Z.; ZHANG, J.; MA,Y.; SONG, S.; GU, W. Biomimetic mineralization of calcium carbonate/carboxymethylcellulose. Mater Sci Eng., v. 32, p. 1982-1987, 2012.

MILLER, L. Use of dinitrosalicyclic acid reagent for determination of reducing sugar. Anal Chem., v. 37, p. 426-428, 1959.

PEDROLLI, D.; MONTERIRO, A.; GOMES, E AND CARMONA, E. Pectin and pectinases: Production, characterization and industrial application of microbial pectinolytic enzymes. TOBIOTJ., v. 3, p. 9-18, 2009.

REHAM, H.; AMAN, A.; SILIPO, A.; QADER, S.; MOLINARO, A. ANSARI, A. Degradation of complex carbohydrate: Immobilization of pectinase from Bacillus licheniformis KIBGE-IB21 using calcium alginate as a support. Food Chem., v. 139, p. 1081-1086, 2013.

SEMENOVA, M.; SINITSYNA, O.; MOROZOVA, V.; FEDOROVA, E.; GUSAKOV, A.; OKUNEV, O.; SOKOLOVA, L.; KOSHELEV, A.; BUBNOVA, T.; VINETSKII, Y.; SINITSYN, P. Use of preparation from fungal pectin lyase in the food industry. Appl Biochem Micro., v. 42, p. 598-602, 2006.

SEENUVASAN,M.; MALAR, C.; PREETHI, S.; BALAJI, N.; IYYAPPAN, J.; KUMAR, M.; KUMAR, K.; Immobilization of pectinase on co-precipitated magnetic nanoparticles for enhanced stability and activity. Res. J. Biotechnol., v. 8, n. 5, p. 24-30, 2013.

SHEN, Q.; YANGA, R.; HUA, X.; YE, F.; ZHANG, W.; ZHAO, W. Gelatin-templated biomimetic calcification for $\beta$-galactosidase immobilization. Process Biochem., v. 46, p. 1565-1571, 2011. 
SIEIRO, C.; GARCÍA-FRAGA, B.; LÓPEZ-SEIJAS, J.; DA SILVA, A.; VILLA, T. Microbial Pectic Enzymes in the Food and Wine Industry. In: VALDEZ, B. Food Industrial Processes- Methods and Equipment. Disponível em: $<\mathrm{http}: / / \mathrm{www}$.intechopen.com/books/food-industrial-processes-methods-andequipment/microbial-pectic-enzymes-in-the-food-and-wine-industry>Acesso em: 18 fev. 2013.

UENOJO, M.; PASTORE, G. Pectinases: Aplicações Industriais e Perspectivas. Quím Nova., v. 30, n. 2, p. 388-394, 2007.

WON, K.; SANGBUM, K.; KWANG-JE, K; HONG, P.; SANG-JI, M. Optimization of lipase entrapment in Ca-alginate gel bead. Process Biochem., v. 40, p. 2149-2154, 2005.

ZHANG, L.; JIANG, Y.; SHI, J.; SUN, X.; LI, J AND JIANG Z. Biomimetic polymerinorganic hybrid microcapsules for yeast alcohol dehydrogenase encapsulation. React Funct Polym., v. 68, p. 1507-1515, 2008. 